\title{
Research on Optimization of Pooling System and Its Application in Drug Supply Chain Based on Big Data Analysis
}

\author{
DengFeng Wu and Hongyi Mao \\ Economics and Management School, Jiujiang University, Jiujiang 332005, China \\ Correspondence should be addressed to DengFeng Wu; wudengfeng1105@hotmail.com
}

Received 30 September 2016; Revised 22 December 2016; Accepted 11 January 2017; Published 15 February 2017

Academic Editor: Xi Zhao

Copyright (C) 2017 DengFeng Wu and Hongyi Mao. This is an open access article distributed under the Creative Commons Attribution License, which permits unrestricted use, distribution, and reproduction in any medium, provided the original work is properly cited.

\begin{abstract}
Reform of drug procurement is being extensively implemented and expanded in China, especially in today's big data environment. However, the pattern of supply mode innovation lags behind procurement improvement. Problems in financial strain and supply break frequently occur, which affect the stability of drug supply. Drug Pooling System is proposed and applied in a few pilot cities to resolve these problems. From the perspective of supply chain, this study analyzes the process of setting important parameters and sets out the tasks of involved parties in a pooling system according to the issues identified in the pilot run. The approach is based on big data analysis and simulation using system dynamic theory and modeling of Vensim software to optimize system performance. This study proposes a theoretical framework to resolve problems and attempts to provide a valuable reference for future application of pooling systems.
\end{abstract}

\section{Introduction}

China has a population of more than 1.3 billion, which is one-fifth of the world population. In the past 30 years, the Chinese government has been pushing reform in the medical care industry to address the increasing demands of citizens for economic development [1]. The use of Internet and mobile technology significantly changes the way of doing business in healthcare industry [2-4]. For example, mobiles become a useful tool in searching health care information, including drugs, doctors, hospital, and treatments [5]. A lot of money has spent on IT projects to improve the service level of health care [6-8]. In 1994, the government started its reform in medical insurance and payment system in two pilot cities, namely, Jiujiang of Jiangxi province and Zhenjiang of Jiangsu province. The argument and exploration regarding medical care reform never ceased since then.

A Centralized Drug Procurement System was implemented in many provinces. This system requires drug suppliers to attend bidding, and only those who win the bidding are provided with the opportunity to sell drugs at the bidding price to public hospitals in the province. In this way, the selection of drug suppliers changes and becomes multiobjective $[9,10]$. This policy aims to reduce price and eliminate corruption in drug procurement. The continuous use of the system generates a large amount of data which is updated every second, forming a complex and difficult environment for the health care reform in every aspect $[11,12]$. This environment will bring extra issues for operations in health care reform [13]. Both formal and informal control should be conducted to increase the system performance $[14,15]$.

Reform means risk, existing in every project [15-17], which also makes sense to the reform project in drug procurement. Two serious issues emerged based on the feedback of parties involved in the drug reform in this big data environment.

(1) Liquidity is increasingly being stressed on suppliers or distributors. According to the survey, the amounts receivable of suppliers in only one province can exceed 1 billion RMB, which is approximately 


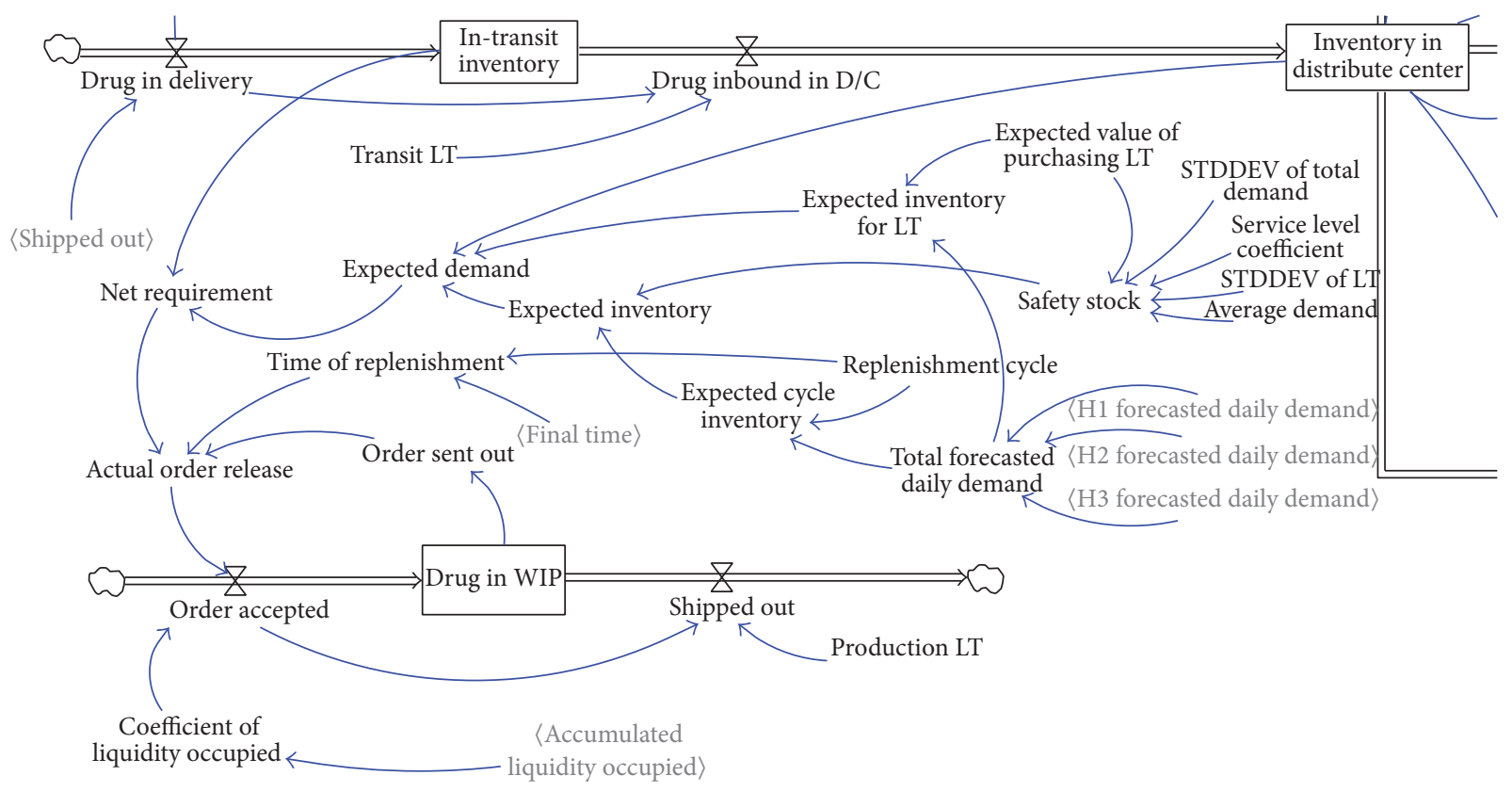

FIgURE 1: Simulation flow chart about process of drug purchasing in traditional model.

equivalent to 160 million USD. Thus, some parties have to delay payment to relieve liquidity stress.

(2) The possibility of drug shortage in public hospitals has increased. Average rate can reach $20 \%$ and occasionally $50 \%$.

The problems mentioned have led to negative impact on drug supply chain and patients. These problems are attributed to the lack of innovation in the supply mode to correspond to the reformed procurement mode. Thus, from the perspective of supply chain, optimizing and adjusting the supply mode are critical to the success of drug procurement reform.

Initially, the project team proposed the use of Drug Inventory Pooling System, which was applied to a number of pilot hospitals and suppliers in Jiujiang City, Jiangxi Province $[1,18]$. At present, Jiujiang University Hospital sponsors four public and one community hospital. One supplier also joined the project.

Feedback for the first eight months of pilot run indicates that the average rate of drug shortage may reach $13 \%$, which is better than the previous rate but worse than expectation. Suppliers expected progress after addressing the liquidity problem, but they remained stressed.

The Inventory Pooling System is an effective method of improving the drug supply chain, but a number of detailed problems should be optimized based on previous research $[1,19]$. To address the problems identified in the pilot run and examine the deficiency of previous research, the present study collects big data from hospital. Based on big data of drug daily demand in hospital, a model is established to simulate variables' change in pooling system and provide solutions. This study is expected to provide a theoretical basis for the optimization of drug supply chain.

\section{Literature Review}

The surrounding conditions used in existing literature on Chinese medical care reform differ from those in other countries. However, we can still find papers that focused on the healthcare industry by employing System Dynamics (SD).

Chahal [20] discussed the process of establishing a hybrid simulation model through SD and discrete event simulation (DES) to resolve problems in the healthcare context.

Mehrjerdi [21] presented a SD model to study interconnections among human being weight, eating habits, exercise, body fat, medication intake, drugs used, and the health problems.

Jia et al. [22] established a model to demonstrate the indepth mechanism of the influence of medicine price policy on drug prescription; this study also proposed countermeasures.

Smith III and Roberts [23] presented a hospital's simulation model of SD to explore the influence of interacting unit capacities on overall efficiency and performance. This study showed the important factors that significantly contribute to the overall performance and efficiency of a hospital enterprise. Based on the SD model, this study applied the sequential bifurcation technique to identify important factors.

Utami et al. [24] focused on the supply chain contract as a dynamic process of cooperative interorganization relationships in the pharmaceutical industry in Indonesia. They aimed to develop a SD model for contracts in the pharmaceutical supply chain by considering price and demand risks to provide alternative policies for an equitable supply chain contract for all parties in the pharmaceutical supply chain.

Behzad et al. [25] established a model and simulated the internal service supply chains of a healthcare system to study the effects of different parameters on the outputs and capability measures of processes. 
The above literature indicates that establishing a simulation model based on SD is a good method to solve problems in a drug supply chain. Good modeling through SD theory is based on big data collection. Effective and costly data collection can help improve the effect and accuracy of simulation.

\section{Establishing a Simulation Model}

Everything in this world is a component of a system [26]. The world we live in is a huge system. Human undergoes the process of exploring the world's structure, components, and interrelations, as well as the interaction of people to master the objective law of the world. People establish diverse mathematical models to describe the objective rules of development. A model is an effective tool for system analysis and system design. The use of mathematical models to conduct system simulation will facilitate the identification of existing problems and intuitively optimize the system [2729].

3.1. Problems Raised. With regard to the drugs "Levofloxacin Hydrochloride and Sodium Chloride injection" in literature 1, the original SD model was established by Vensim software based on daily demand data of the drug in 2.5 years in three sample hospitals. That model contains the following problems.

(1) The Influence of Key Variables in the Optimization of the Pooling System Has Not Been Completely Studied. The original model was established in one chapter of the dissertation. Given the limited space in the dissertation, a few key variables of Inventory Pooling System, such as "purchasing leading time," "replenish cycle," and "service level of safety stock" and their influence on "liquidity occupied" and "drug shortage rate," have not been discussed. Finding the best value of variables using the simulation model is necessary because adjusting those variables will directly affect the performance of the pooling system.

(2) The Relationship between Pooling System and a Number of Sample Hospitals Has Not Been Discussed. The original model was subjected to a number of sample hospitals. Thus, data were based on only three hospitals. The amount of liquidity required and the change in drug shortage were not discussed when more than three hospitals are involved in a system. Traditionally, involvement of several hospitals will result in obvious scale effect of the pooling system. Simulation will help suggest accurate scale and range.

(3) Calculation of Purchasing Volume Should Be Reasonable. In the original model (Figure 1), reasoning about purchasing volume in distribution center is not reasonable. In the new model, procurement theory of P-system [30] and the process of maximizing demand volume to net requirement volume and placing order in procurement will be simulated and modeled.

(4) The Root Causes That Resulted in the Reduced Inventory Level in a Supply Chain and Its Improvement Were Not
Discussed. In a pooling system, inventory level reduction may be attributed to the following factors:

(a) Less procurement cycle and high frequency of placing an order.

(b) The pooling system has its own inherent advantage. Therefore, even in a similar situation, the application of pooling system will reduce inventory.

History literature, which is a primary factor in the preceding causes, has never been discussed. However, history literature can assist in finding solutions to optimize the pooling system. If the first item works, then improving the purchasing cycle and frequency can be a good option. If the second item works, then the next step should involve additional hospitals for improved optimization.

(5) Inadequate Reality Checks. By taking Hospital H1 as example, the original model equation of drug distribution is set as

drug delivered to $\mathrm{H} 1$

$=\operatorname{MIN}(\operatorname{MAX}(\operatorname{MAX}(\mathrm{H} 1$ hospital planned order

- H1 hospital inventory, 0),

$\operatorname{MAX}(\mathrm{H} 1$ daily demand from patient

- H1 hospital inventory, 0)),

Inventory in Distribute center).

The equation obtains a minimum value between hospital demand and inventory level in the distribution center $(D / C)$ as delivered volume to ensure $\mathrm{D} / \mathrm{C}$ inventory is not less than zero. When only one hospital has a demand, the result is considered true. However, in a pooling system, total demand from multihospitals is occasionally larger than $\mathrm{D} / \mathrm{C}$ inventory though the demand of each hospital is smaller than D/C inventory (shown in Figure 2). In that case, D/C inventory will be negative and will result in simulation failure (shown in Figure 3).

3.2. Remodeling. Final time is 360 days and time step is one day in the new model. SD was established by Vensim software (Figure 4).

A few changes were introduced into the new model based on the original model in literature 1 .

3.2.1. Equation Setting for Nonnegative Number of D/C Inventory Level. The model added the variable "distributing ratio from center to hospital" to compare $\mathrm{D} / \mathrm{C}$ inventory and the total demand of hospitals and increase inventory level in the simulation model to higher than zero. The division of these two factors is fulfillment rate. 


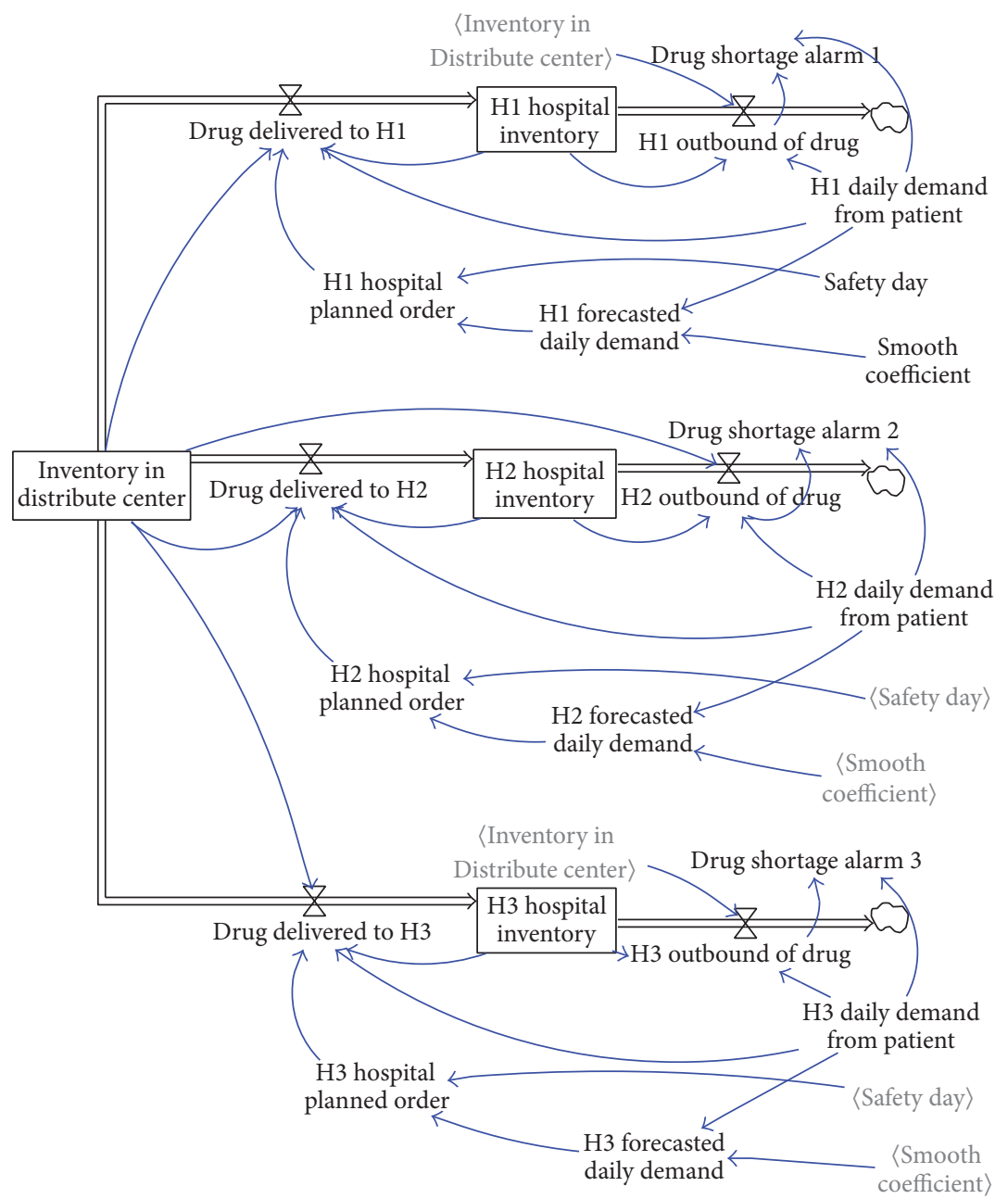

Figure 2: Simulation flow chart regarding drug delivered from D/C to the hospital in the old model.

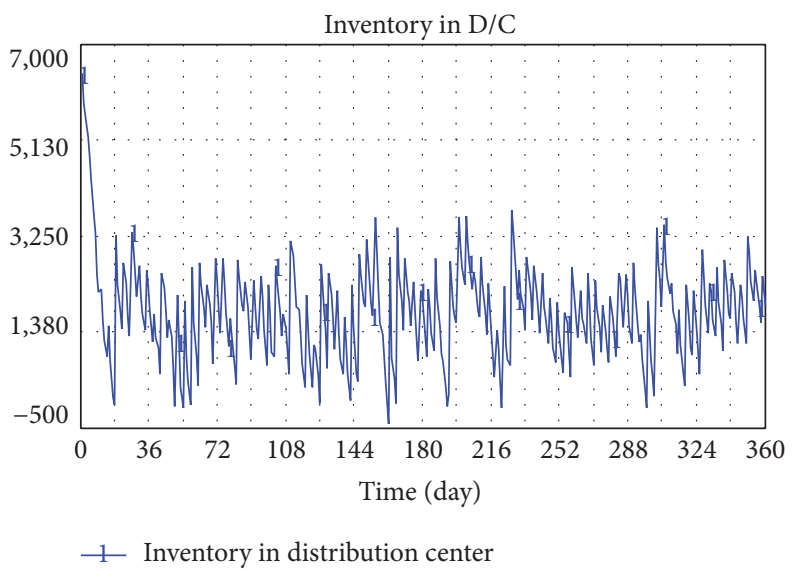

Figure 3: Simulation of inventory in $\mathrm{D} / \mathrm{C}$ in a few situations in the original model. 


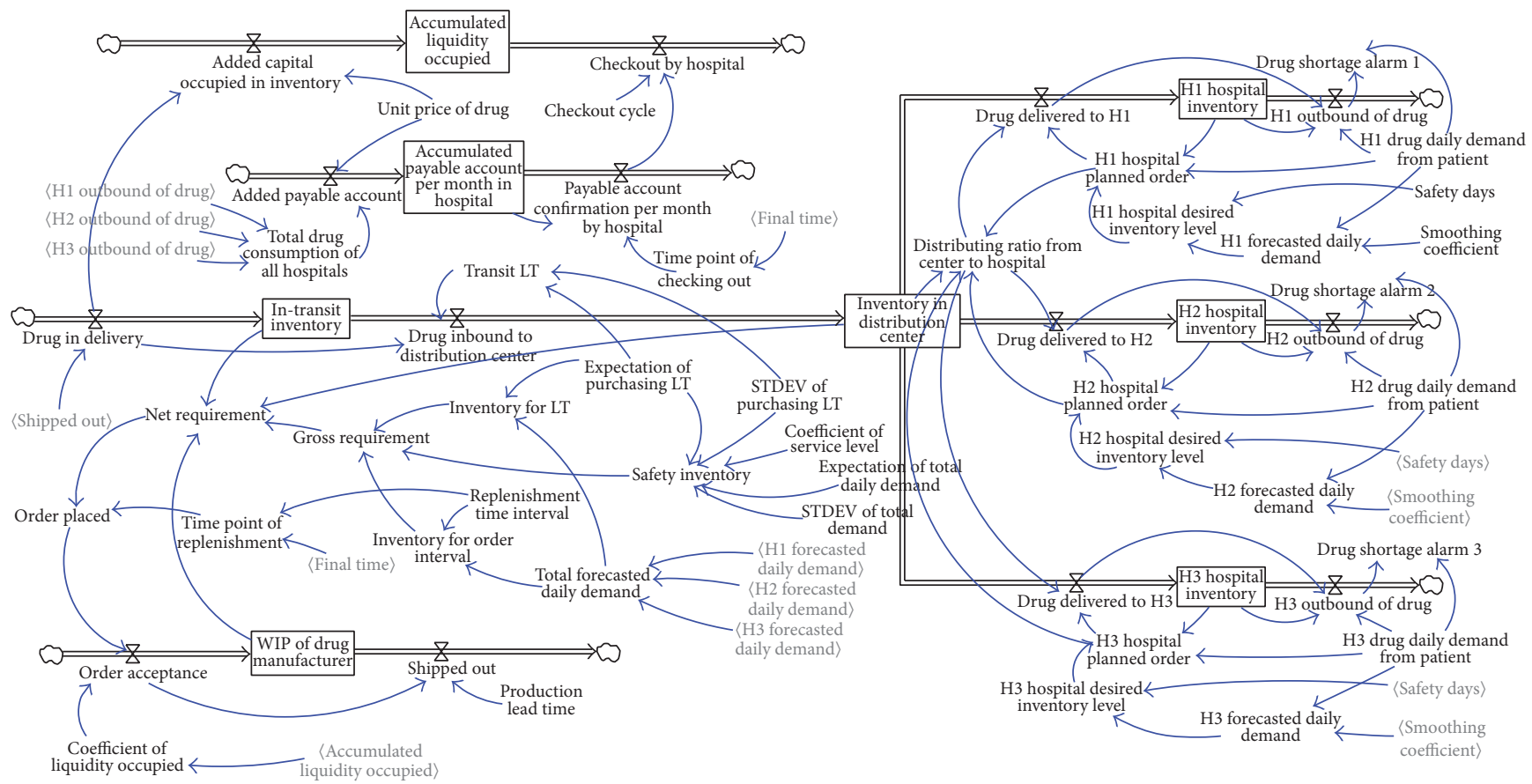

FIGURE 4: Simulation flow chart model after improvement.

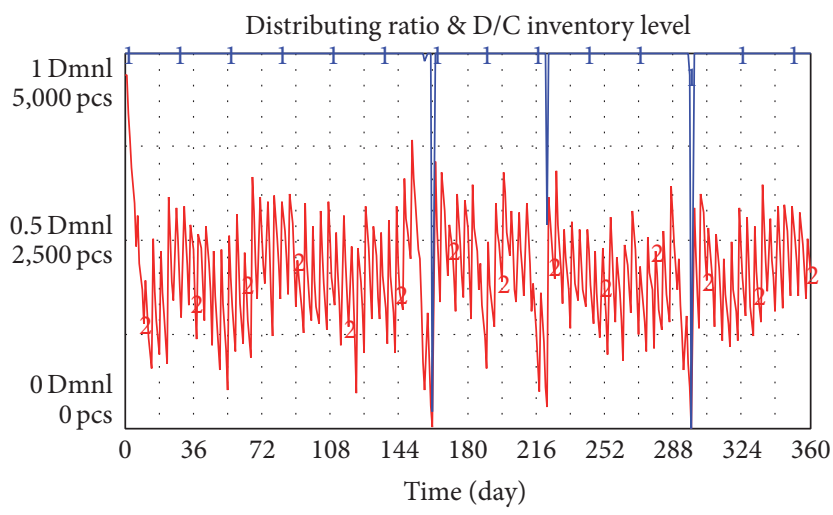

Distributing ration from center to hospital $-1-\mathrm{Dmnl}$

Inventory in distribution center $\quad 2$ pcs

Figure 5: D/C inventory level and distributing ratio.

Distribution ratio from center to hospital = IF THEN ELSE $($ H1 hospital planned order

$+\mathrm{H} 2$ hospital planned order $+\mathrm{H} 3$ hospital planned order $>$ Inventory in distribution center,

$\left.\frac{\operatorname{Max}(\text { Inventory in distribution center, } 0)}{(\mathrm{H} 1 \text { hospital planned order }+\mathrm{H} 2 \text { hospital planned order }+\mathrm{H} 3 \text { hospital planned order })}, 1\right)$,

drug delivered to $\mathrm{H} 1=\mathrm{H} 1$ hospital planned order $*$ distributing ratio from center to hospital.

Figure 5 shows the result of simulation. The figure shows that inventory in $\mathrm{D} / \mathrm{C}$ sometimes fails to meet demand, which may cause supply break. However, inventory level is always larger than or equal to zero. 


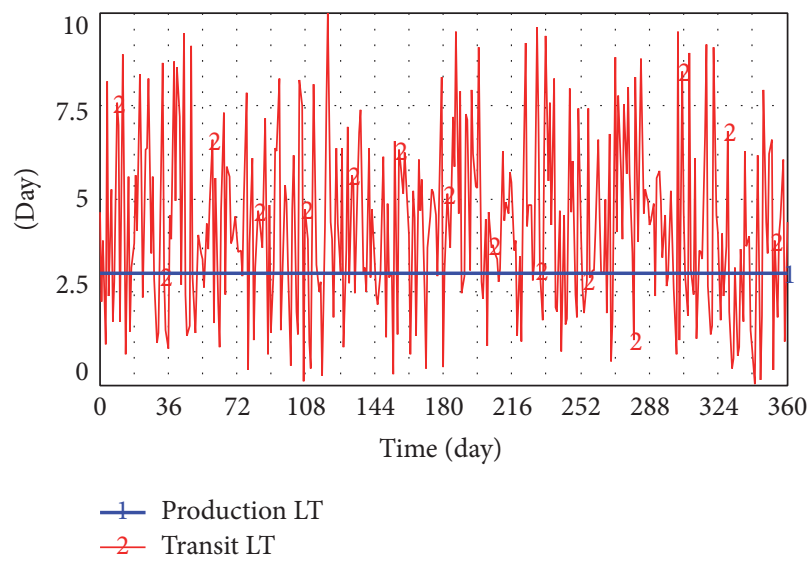

Figure 6: Simulation of Production LT and Transit LT.
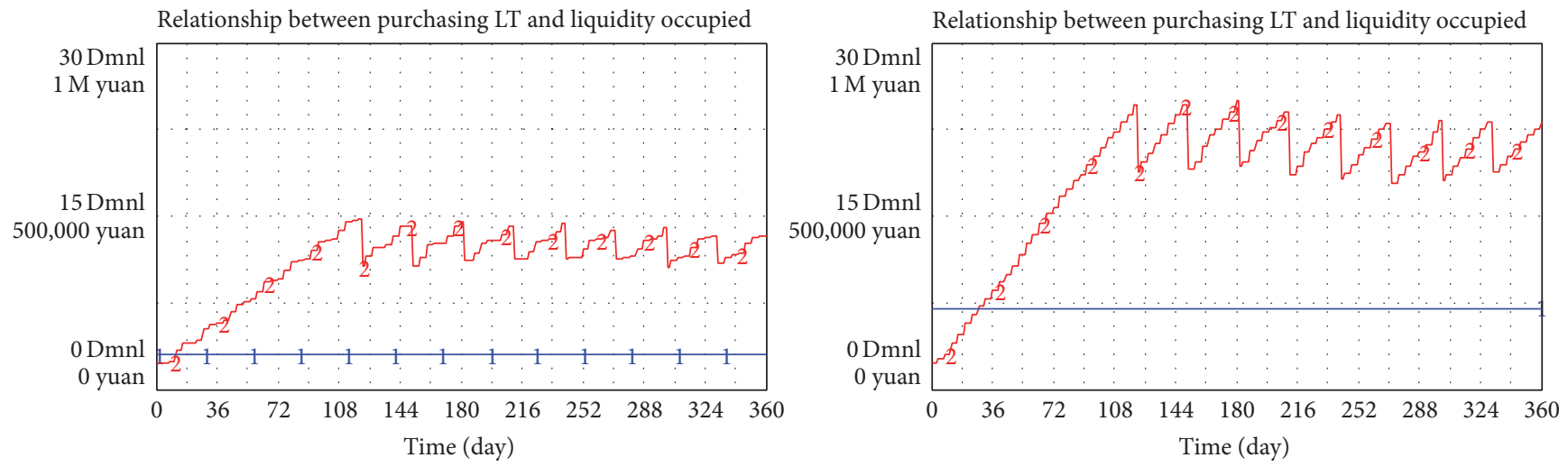

Expected value of purchasing LT $-1-$ Dmnl

Expected value of purchasing LT $-1-$ Dmnl

Accumulated liquidity occupied $\quad-2$ yuan

Accumulated liquidity occupied $\quad-2$ yuan

Relationship between purchasing LT and liquidity occupied

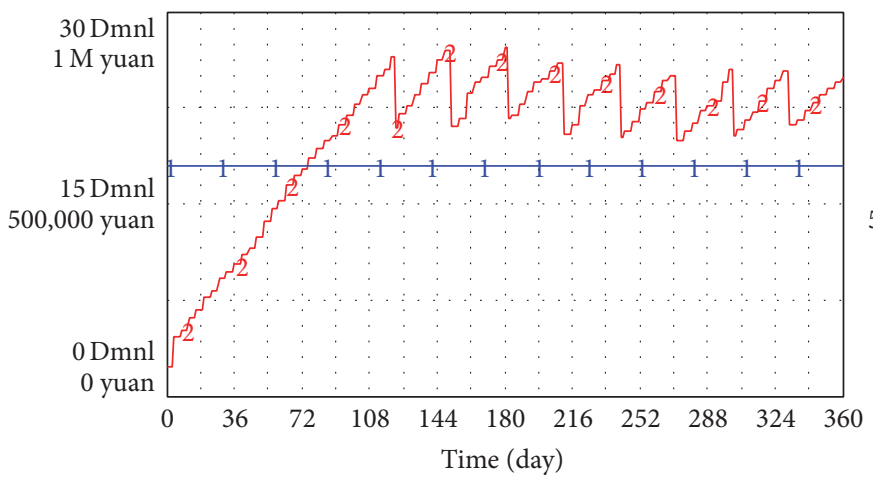

Relationship between purchasing LT and liquidity occupied

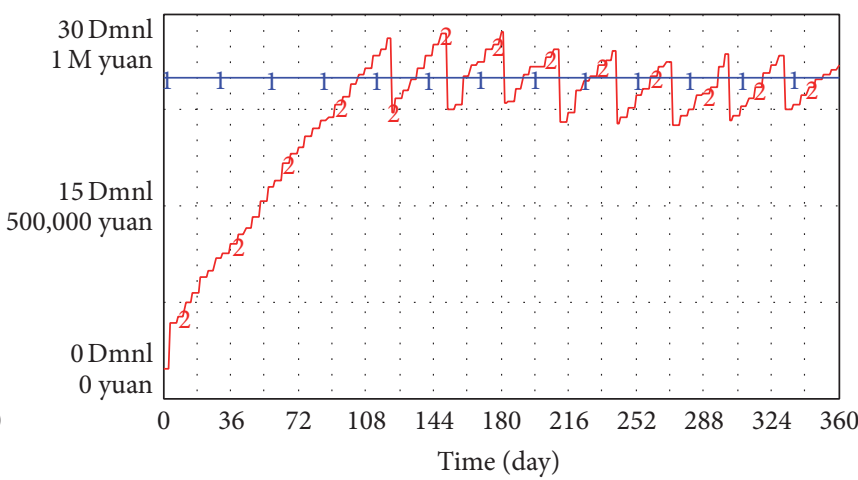

Expected value of purchasing LT $\rightarrow$ Dmnl Accumulated liquidity occupied $\quad-2$ yuan

Expected value of purchasing LT $\quad 1-$ Dmnl Accumulated liquidity occupied -2 yuan

FIGURE 7: Relationship between purchasing LT and liquidity occupied. 

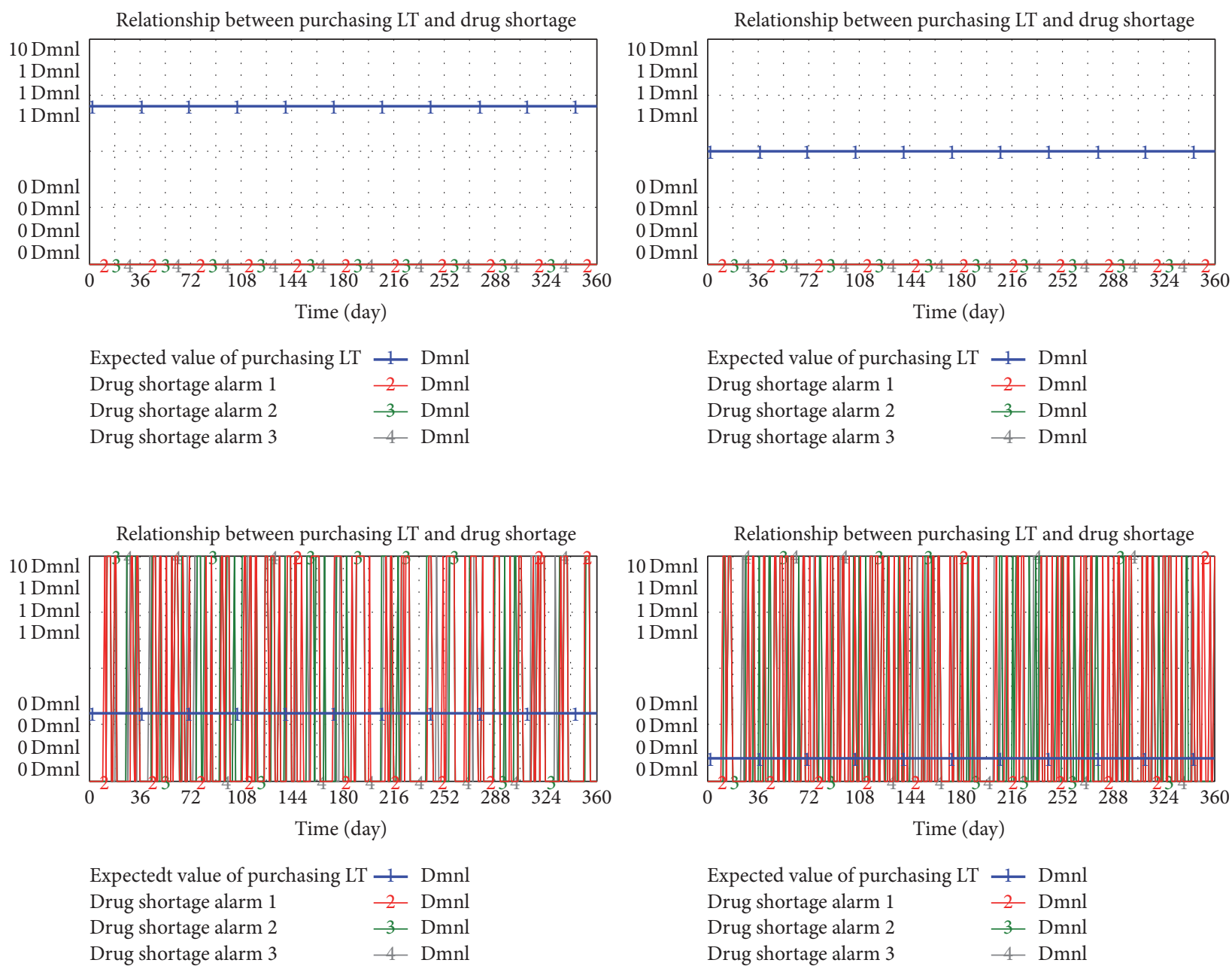

FIGURE 8: Relationship between purchasing LT and drug shortage.

3.2.2. Optimize the Process of Placing Order. According to the classic $\mathrm{P}$-system ordering theory, the relationship between factors in the new model is given as

$$
\begin{aligned}
\text { Gross requirement }= & \text { inventory for LT } \\
& + \text { inventory for order interval } \\
& + \text { safety inventory. }
\end{aligned}
$$

Net requirement is the gap between gross requirement and current inventory, which include inventory in transit, $\mathrm{D} / \mathrm{C}$, and WIP (work in process).

Net requirement $=\operatorname{Max}$ (gross requirement

$$
\begin{aligned}
& \text { - "In-transit inventory" } \\
& \text { - Inventory in distribution center } \\
& \text { - WIP of drug manufacturer, 0), }
\end{aligned}
$$

Order placed $=$ net requirement
* time point of replenishment,

Time point of replenishment $=$ PULSE TRAIN $(0,1$,

REPLELISHMENT TIME INTERVAL, FINAL TIME),

here REPLELISHMENT TIME INTERVAL is four days.

3.2.3. Modeling of Purchasing Leading Time (LT). According to a survey, the expected value of lead time of Levofloxacin Hydrochloride and Sodium Chloride injection is seven days, whereas its standard deviation is three days. The entire purchasing L/T comprises the production and transit period. This study focuses on drug distribution supply chain without loss of generality. Production period is set as constant at three days. The transit period fits the normal distribution with its expected value of four days.

TRANSIT $\mathrm{LT}=$ random normal $(0,10$,

EXPECTATION OF PURCHASING LT - 3, 


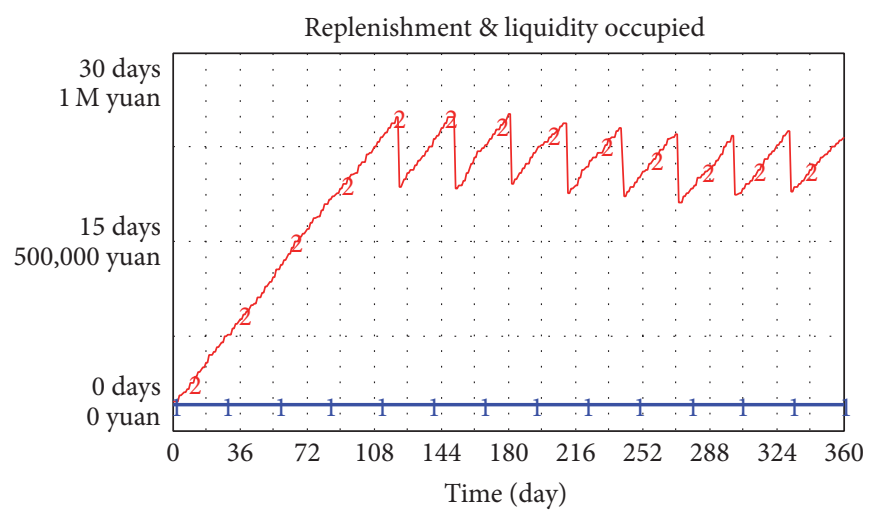

Replenishment time interval $\quad+$ day Accumulated liquidity occupied -2 yuan

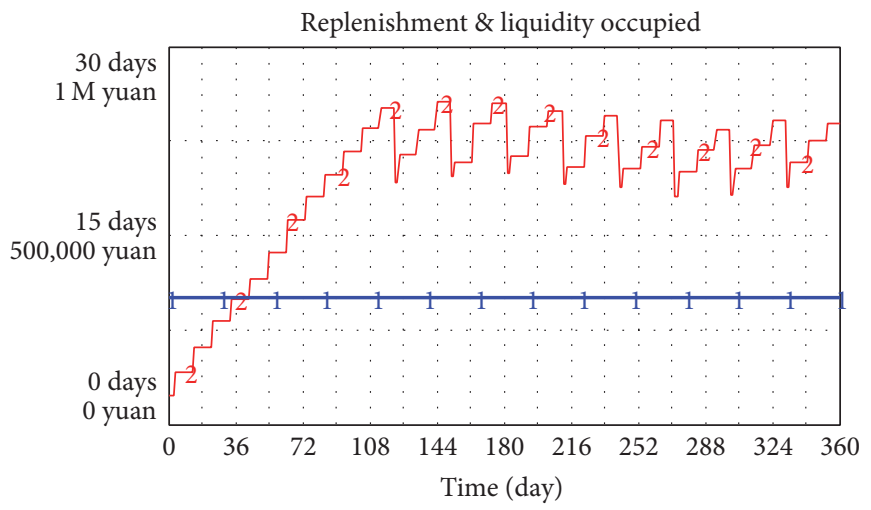

Replenishment time interval $\quad 1-$ day Accumulated liquidity occupied -2 yuan

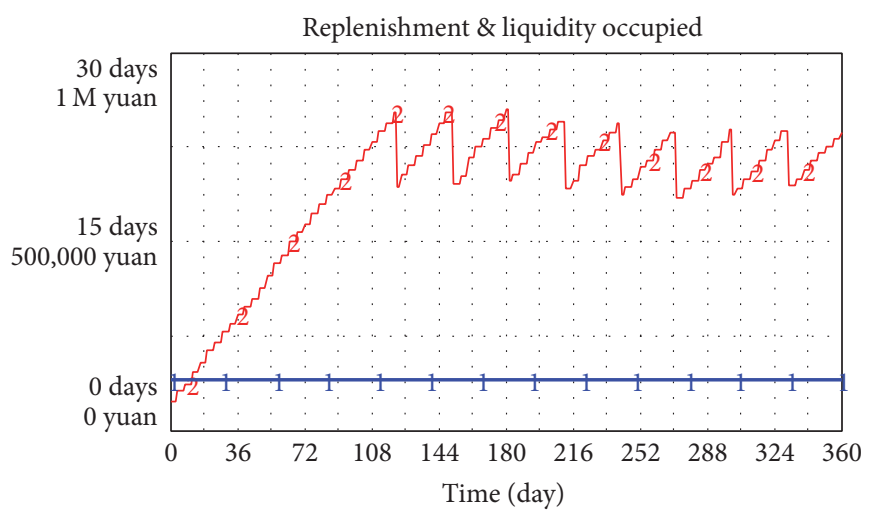

Replenishment time interval + day Accumulated liquidity occupied -2 yuan

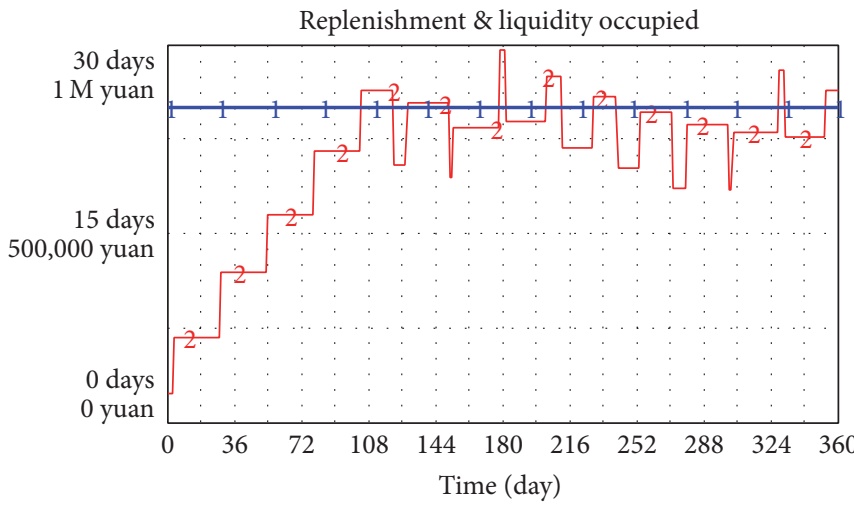

Replenishment time interval $\quad 1$ day Accumulated liquidity occupied 2 yuan

FIGURE 9: Relationship between replenishment cycle and liquidity.

In the preceding equation, the expected value of Transit LT is set as purchasing LT minus 3. Transit LT will synchronously vary when the expected value and STD deviation of purchasing LT are diminished (shown in Figure 6).

\section{Inventory Pooling Optimized by Key Variables}

Setting a few important variables and indexes in the pooling system will directly and obviously affect its effects [31, 32]. Based on the problems raised in background analysis, variables "accumulated liquidity occupied" and "drug shortage ratio" are selected as key indexes to measure the application effect of the pooling system. The definition of the former index is liquidity receivable but occupied in related links, such as in transit, $\mathrm{D} / \mathrm{C}$, and hospitals. The latter is the number of drug shortage times in a simulation life cycle.

\subsection{Purchasing L/T and Replenish Cycle Adjustment}

4.1.1. Lead Time. In similar surroundings and parameters, purchasing L/T is separately set as $3,9,18$, and 25 days to simulate the relationship between $\mathrm{L} / \mathrm{T}$ and liquidity occupied.
In Figure 7, liquidity continuously increases (curve in red) with the increment of $\mathrm{L} / \mathrm{T}$ (transverse line in blue). $\mathrm{L} / \mathrm{T}$ has a proportional relationship with liquidity occupied in a supply chain; however, the relationship is not always linear. The increment rate of liquidity gradually slowed down. In summary, shortening L/T will benefit the reduction of liquidity occupied.

Without other changes in the surroundings and variables, $\mathrm{L} / \mathrm{T}$ is separately set as $7,5,3$, and 1 day to simulate its relationship with drug shortage.

In Figure 8, cutting down L/T (transverse line) will not increase the frequency of shortage (vertical line obviously). However, a relatively short L/D (such as 3 or 1 day in the figure) will result in a drastic increment of the shortage because a short L/D will lead to low-level safety stock. Once the random demand in the end of the supply chain drastically and unexpectedly fluctuates, the drug will be out of stock and supply breaks. In other words, pursuing a relatively short L/D is unnecessary for parties involved to reduce risk of shortage in a drug pooling system.

4.1.2. Replenish Cycle. Replenish cycle is the interval between two consecutive order placements. In the same surrounding 

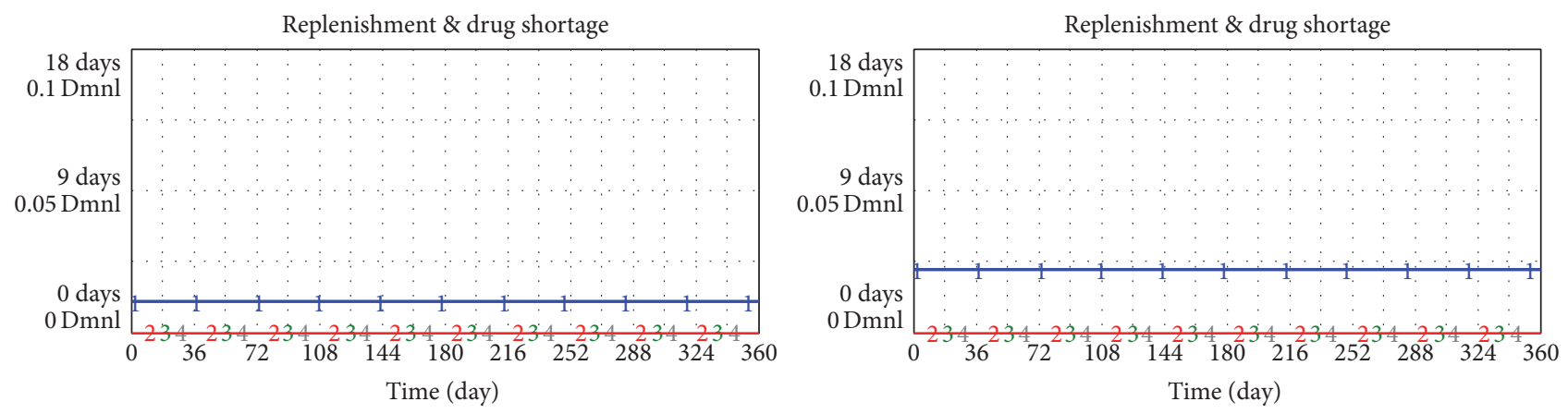

$\begin{array}{lll}\text { Replenishment time interval } & 1-\text { day } \\ \text { Drug shortage alarm 1 } & -2 & \text { Dmnl } \\ \text { Drug shortage alarm 2 } & -3 & \text { Dmnl } \\ \text { Drug shortage alarm 3 } & -1 & \text { Dmnl }\end{array}$

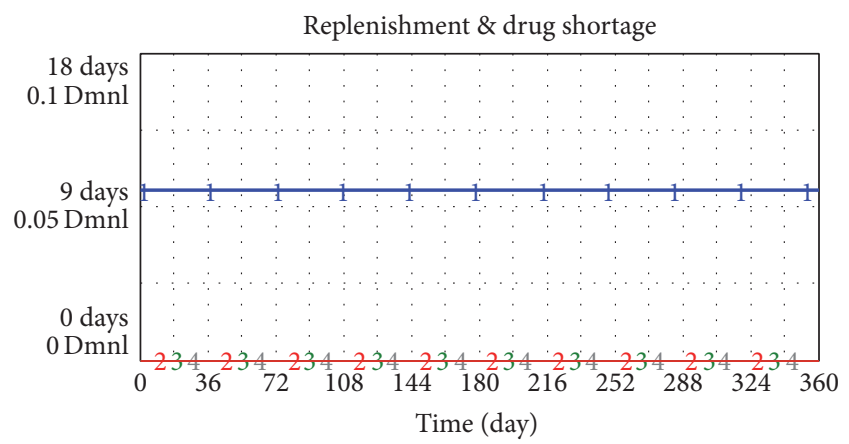

$\begin{array}{lll}\text { Replenishment time interval } & 1-\text { day } \\ \text { Drug shortage alarm 1 } & 2 & \text { Dmnl } \\ \text { Drug shortage alarm 2 } & -3 & \text { Dmnl } \\ \text { Drug shortage alarm 3 } & -4 & \text { Dmnl }\end{array}$

$$
\begin{aligned}
& \text { Replenishment time interval }-1-\text { day } \\
& \text { Drug shortage alarm } 1 \quad 2 \quad \text { Dmnl } \\
& \text { Drug shortage alarm } 2 \quad 3-\text { Dmnl } \\
& \text { Drug shortage alarm } 3 \quad 4 \quad \mathrm{Dmnl}
\end{aligned}
$$

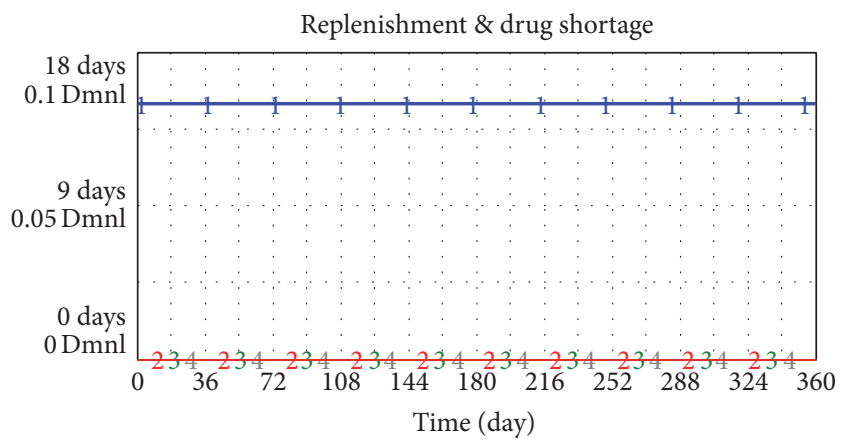

$$
\begin{aligned}
& \text { Replenishment time interval } 1+\text { day } \\
& \begin{array}{lll}
\text { Drug shortage alarm } 1 & 2 & \text { Dmnl }
\end{array} \\
& \text { Drug shortage alarm } 2 \quad 3-\mathrm{Dmnl} \\
& \text { Drug shortage alarm } 3 \quad 4 \quad \text { Dmnl }
\end{aligned}
$$

Figure 10: Relationship between replenishment cycle and drug shortage.

and other variables, the cycle time will be set as 2, 4, 10, and 25 days to simulate the change of liquidity occupied.

In Figure 9, liquidity occupied (curve line) will slightly increase with the increment of replenish cycle (transverse line). In the simulation model, the corresponding average value is 620837, 626727, 644285, and 690170, whereas the maximum value is $824869,838331,852919$, and 940703 . The minimum value, which is the default value, is 98214 . The root cause leading to this trend is as follows:

(a) Liquidity occupied is mainly influenced by the cycle of payment settlement.

(b) The maximum inventory in $\mathrm{D} / \mathrm{C}$ comprises three parts, namely, inventory in replenish cycle, $\mathrm{L} / \mathrm{T}$, and safety stock. The increment of time cycle only affects the inventory in the replenish cycle but not either. Overall, the inventory is only slightly influenced.

(c) Annual total demand remains stable.

Other conditions remain unchanged. Replenishment cycle is set as 2, 4, 10, and 15 days to simulate the times of drug shortage.

When cycle time (transverse line) increases, drug shortage frequency remains stable because drug shortage is only related to safety stock level instead of replenish cycle (shown in Figure 10). The latter decides the inventory in its own period.

4.2. Service Level. "Service level" describes the degree to which inventory addresses demand and is presented as a percentage. According to the Normal Distribution Chart, when the service level of safety stock is set as 98\%, 95\%, 90\%, and $80 \%$, the corresponding service coefficient will be 2.05 , $1.65,1.30$, and 0.85 , respectively. Once these values are placed in the formula, the relation between service level and KPI can be shown in Figure 11.

Service level has no obvious effect on KPI. Based on the details of the simulation data, when the service level changed from $98 \%$ to $90 \%$, the average inventory level of the supply chain dropped to 4730 , which achieved $17.32 \%$ improvement compared with 5720 (98\%). Before service level changed to $90 \%$, the frequency of drug shortage remained zero even when below $90 \%$. Thus, drug shortage has never occurred.

4.3. Analysis of Additional Hospital Involvement in the Pooling System. Existing studies are based on the situation of three 

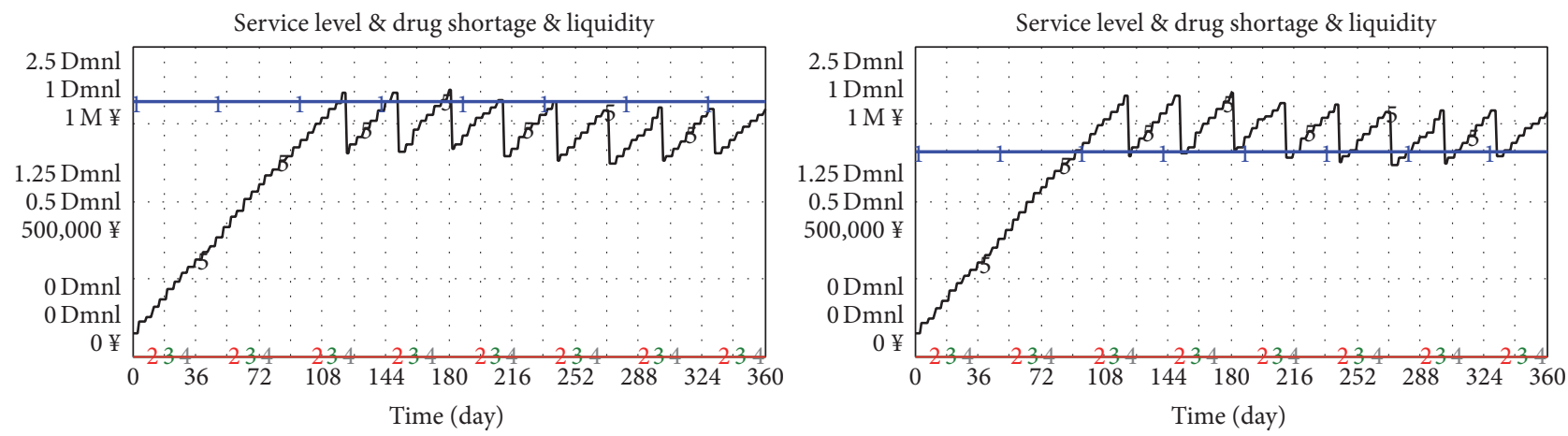

$\begin{array}{ll}\text { Coefficient of service level } & 1-\mathrm{Dmnl} \\ \text { Drug shortage alarm 1 } & 2-\mathrm{Dmnl} \\ \text { Drug shortage alarm 2 } & -3-\mathrm{Dmnl} \\ \text { Drug shortage alarm 3 } & -4 \text { Dmnl } \\ \text { Accumulated liquidity occupied } & -5-¥\end{array}$

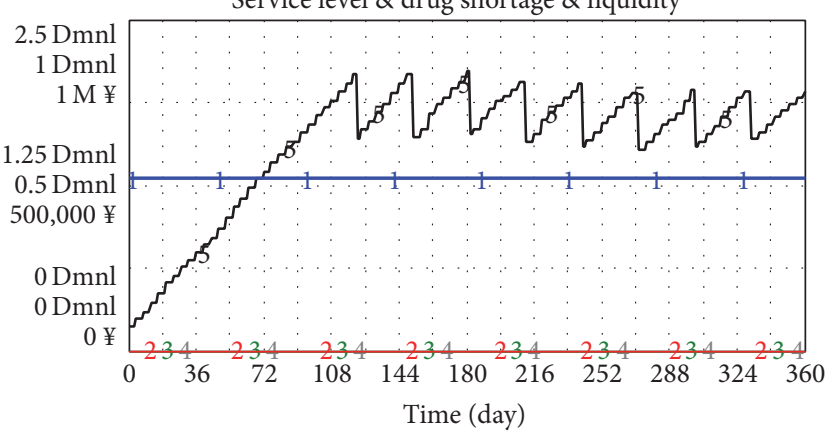

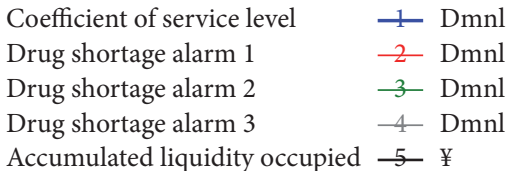

\begin{abstract}
Coefficient of service level $\quad 1 \quad \mathrm{Dmnl}$
Drug shortage alarm $1 \quad 2 \quad$ Dmnl

Drug shortage alarm $2 \quad 3-\mathrm{Dmnl}$

Drug shortage alarm $3 \quad-4$ Dmnl

Accumulated liquidity occupied $\stackrel{5}{-} ¥$
\end{abstract}

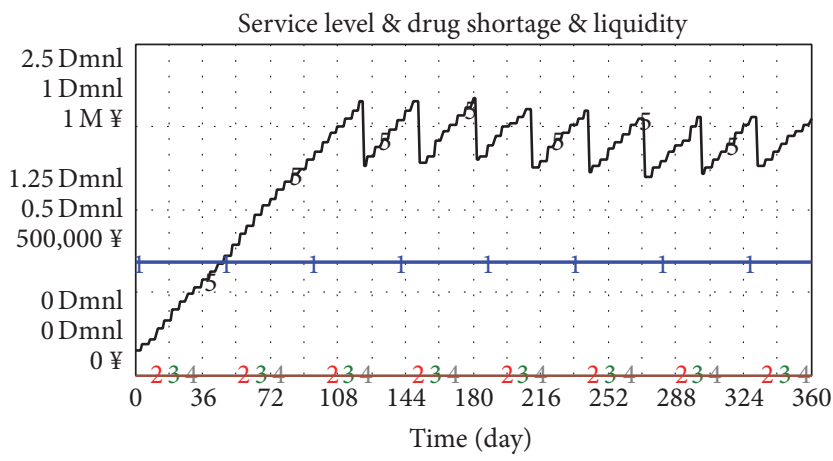

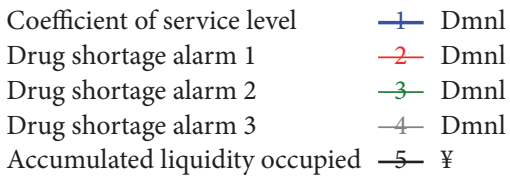

FIGURE 11: Relationship among service level, drug shortage, and liquidity occupied.

sample hospitals involved in the pooling system based on data in early investigation. The process of increasing KPI if additional hospitals join the system is discussed.

The involvement of additional hospitals should have the same possibility distribution with the three sample hospitals in a daily demand because all data were obtained from three hospitals based on the early investigation for easy comparison without loss of generality.

In the new model, similar data features, such as expected value and standard deviation of daily demand as number 1 and number 3 hospitals and number 10 and number 30 hospitals respectively, are involved in the pooling system. The flow chart of the pooling system of five hospitals is shown in Figure 12 to save space.

The simulation result shows that the total frequency of drug shortage occurred 234 times after five hospitals were involved (shown in Figure 13), which indicates 47 times for one hospital on average and the shortage rate is approximately $13 \%$ in 360 days in one year.
The main reason attributed to drug shortage is that suppliers need to address increased hospital demands and liquidity required rapidly increased thereby resulting in liquidity rupture and supply break.

Based on the analysis, the following measures can be applied to relieve stress of liquidity required: (a) finance increased liquidity; (b) accelerate rotation of liquidity.

According to government policy, hospitals should settle their accounts with suppliers in 90 days only after obtaining drugs. However, in the Centralized Drug Procurement System, a supplier winning a bid may gain an opportunity to provide drugs to all public hospitals in a provincial scope, which will lead to an enormous supply. Once the 90-day cycle of payment is completed, liquidity may be at risk of rupture. The trend attributed to the shortening payment cycle should be discussed.

In unchanged conditions, the set cycle of payment is 90 , 60,30 , and 0 days ( 0 day means to pay by the end of the month). 


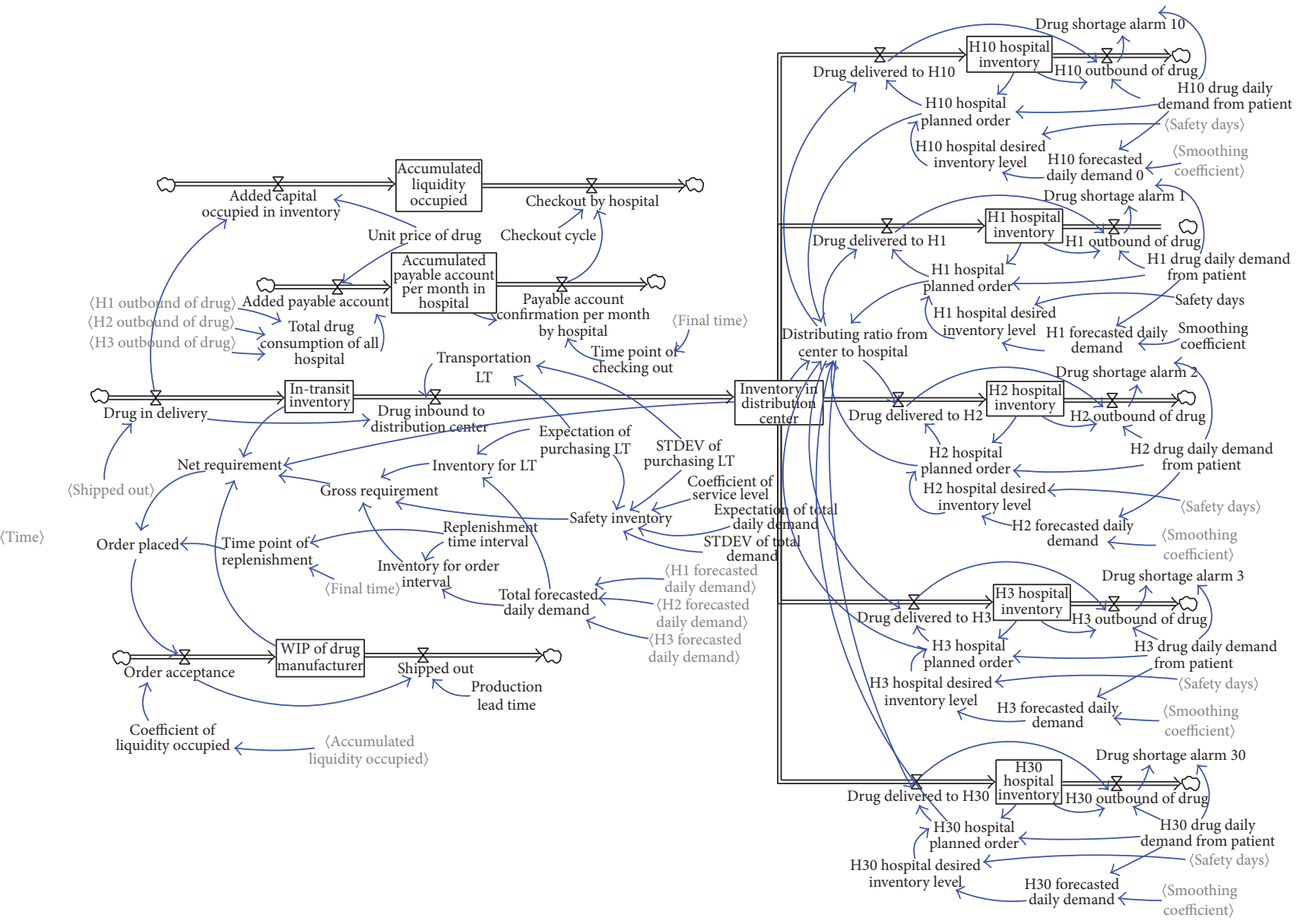

FIgURE 12: Simulation of five hospitals involved in the Inventory Pooling System.

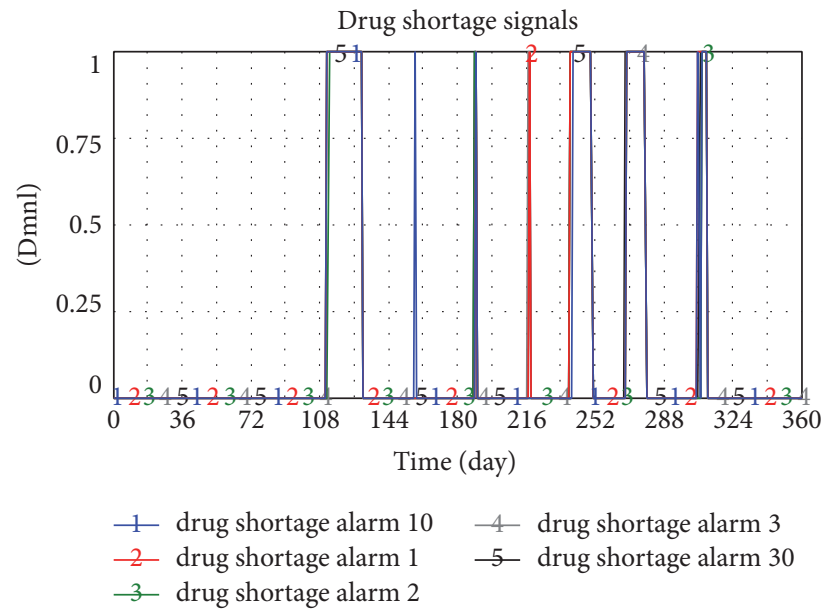

FIGURE 13: Drug shortage when five hospitals join the pooling system. 

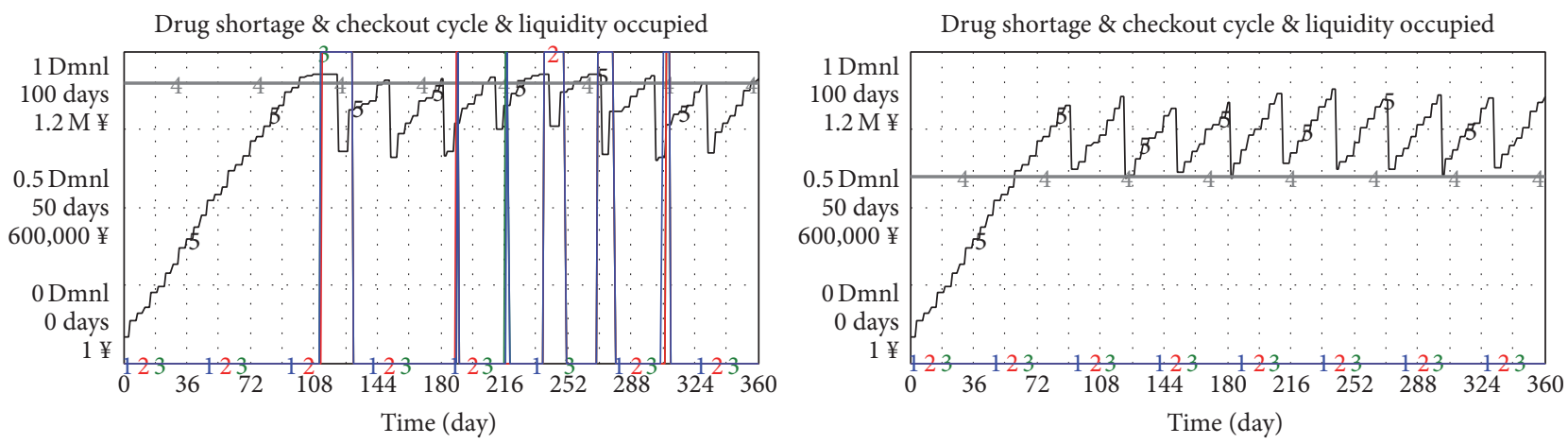
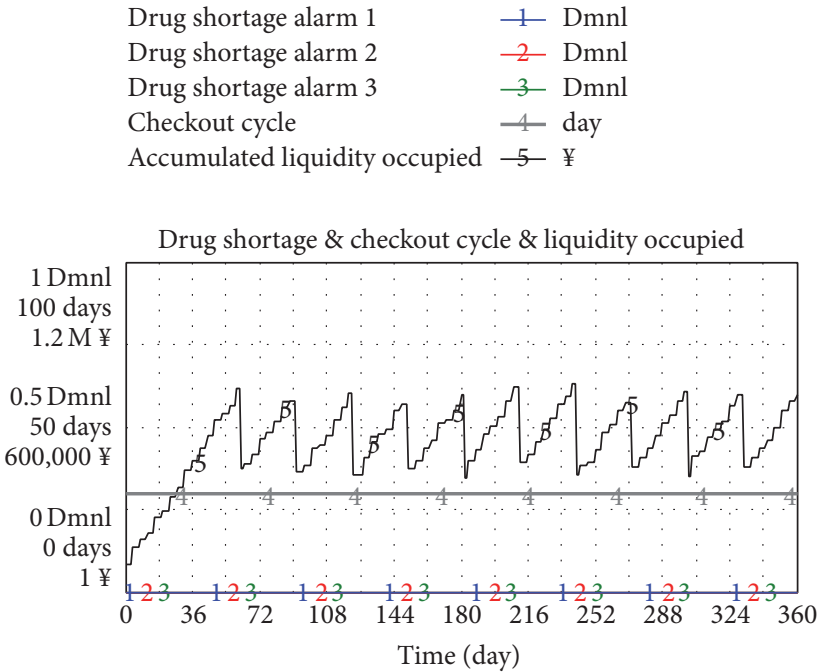

\begin{abstract}
Drug shortage alarm $1 \quad 1-\mathrm{Dmn}$ Drug shortage alarm $2 \quad-2 \quad$ Dmnl Drug shortage alarm $3 \quad 3-\mathrm{Dmnl}$ Checkout cycle $\quad-4$ day Accumulated liquidity occupied $\stackrel{5}{-} ¥$
\end{abstract}

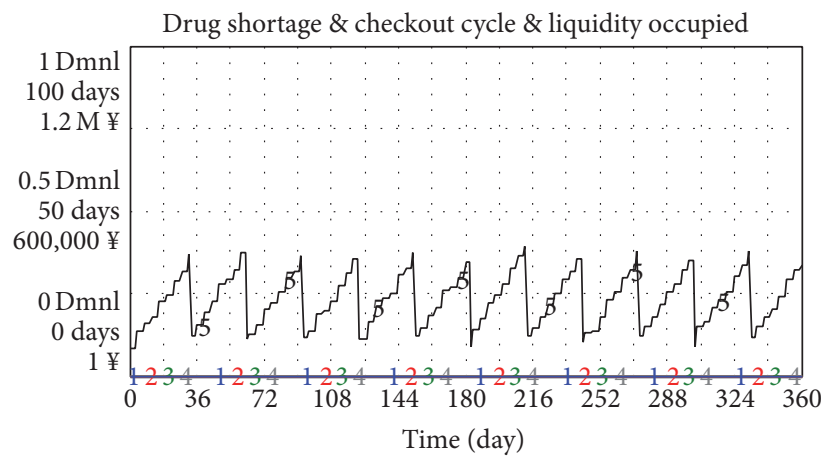

$\begin{array}{ll}\text { Drug shortage alarm 1 } & 1-\mathrm{Dmnl} \\ \text { Drug shortage alarm 2 } & -2 \text { Dmnl } \\ \text { Drug shortage alarm 3 } & -3-\mathrm{Dmnl} \\ \text { Checkout cycle } & -4 \text { day } \\ \text { Accumulated liquidity occupied } & -5-¥\end{array}$

$$
\begin{array}{ll}
\text { Drug shortage alarm 1 } & 1-\text { Dmnl } \\
\text { Drug shortage alarm 2 } & 2-\text { Dmnl } \\
\text { Drug shortage alarm 3 } & -3-\text { Dmnl } \\
\text { Checkout cycle } & -4 \text { day } \\
\text { Accumulated liquidity occupied } & 5-¥
\end{array}
$$

FIGURE 14: Relationship between checkout cycle and KPI when five hospitals are involved in a pooling system.

Figure 14 shows that the liquidity stress and shortage rate improved with the shortened payment cycle. When the payment cycle is set at 60 days or below, the shortage has never occurred again in three hospitals.

\section{How Does the Pooling System Improve KPI}

Traditionally, a pooling system has a natural advantage in cutting down the inventory level in a supply chain. However, this study shows that inventory drop is caused by the shortened replenish cycle.

In literature 1, the replenishment cycle in a traditional model is 30 days. Replenishment cycle improved to 30 days in the pooling system without any other change.

Figure 15 shows that the total inventory of the entire drug supply chain in the pooling system is 10952 . Inventory in three hospitals, inventory in $\mathrm{D} / \mathrm{C}$, and in-transit inventory are 124 , 148, 192, 9112, and 1382.

In literature 1, replenish cycle is 30 days in a traditional procurement model. Inventory in three hospitals and transit is shown in Figure 16. The entire supply chain of three hospitals is accumulated to 9178 .
The replenish cycle of the pooling system to be applied will be promoted to 30 days. The average inventory level in a supply chain of drug distribution is 11649. Inventory in three hospitals, inventory in $\mathrm{D} / \mathrm{C}$, and in-transit inventory are 124, $148,192,9823$, and 1362 . The annual average inventory of the distribution supply chain is 5778 to shorten the replenish cycle to four days.

Analysis indicates that the pooling system cannot directly and obviously reduce inventory in a supply chain. However, given that the pooling system is implemented by a professional Third Party Logistics (TPL) instead of the hospital, frequent and small-scale purchase and distribution become possible. Inventory level will drop with purchasing scale reduction. Cutting down inventory cannot improve the status of liquidity stress because the latter is mainly influenced by payment cycle.

\section{Conclusion}

A few principles should be emphasized after the application of the pooling system to relieve stress of liquidity and reduce the frequency of drug shortage. 


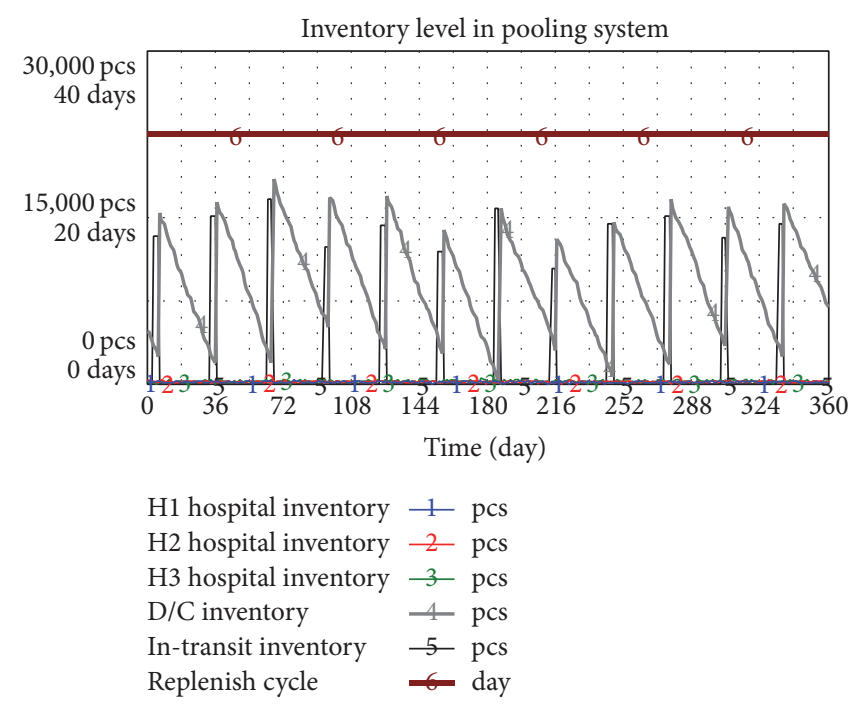

FIGURE 15: Inventory of the entire supply chain of pooling system.
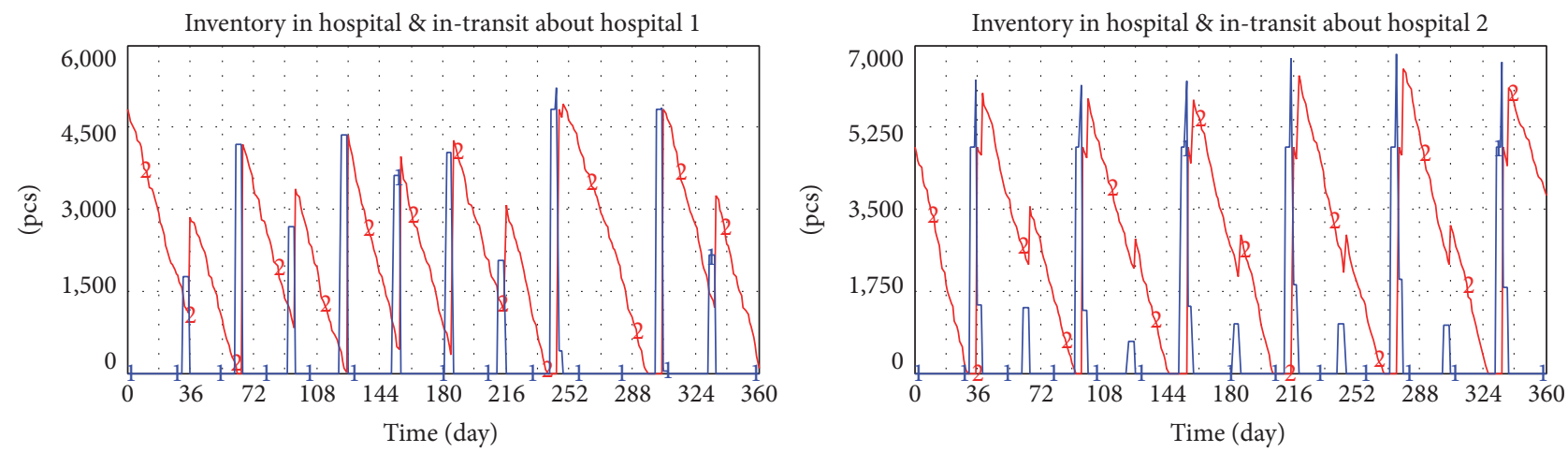

$1-$ "In-transit inventory": hospital 1
2 Hospital inventory: hospital 1

1 "In-transit inventory": hospital 2

2 Hospital inventory: hospital 2

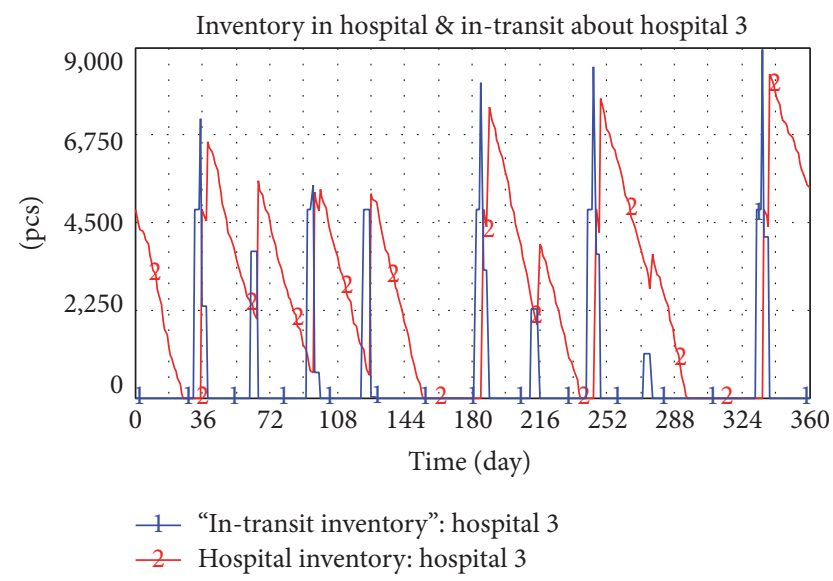

FIGURE 16: Inventory level in the traditional drug procurement model. 
(1) Shortening Payment Cycle to Reduce Liquidity Occupied. After a government-oriented bidding system is applied in the drug purchasing industry, a supplier who wins the bid will gain the opportunity to supply all hospitals in one provincial scope. This process may result in a sharper supply volume surge than in history data and liquidity stress. Given the shortened payment cycle, liquidity amount will considerably decline because payment cycle can affect the amount of liquidity. Thus, when creating centralized purchasing laws, the government should require a short payment cycle to streamline the supply chain.

(2) Suppliers Should Shorten Replenishment Cycle to Cut down the Inventory Level. The replenish cycle should be shortened to reduce inventory. Otherwise, the payment cycle should be shortened to relieve liquidity stress.

(3) Suppliers Should Not Set a Relatively Short Leading Time of Procurement. Traditionally, short lead time is good for lowlevel inventory, good liquidity status, and quick response to the market. However, as per simulation, a relatively short leading time will also increase the risk of shortage. The supplier should set a reasonable lead time to balance different influences from $\mathrm{L} / \mathrm{T}$.

(4) Service Level of Safety Stock Should Be Proper. A considerably high service level of safety stock will reduce the risk of drug shortage but increase the liquidity and inventory level. Once liquidity rupture occurs, consecutive supplies will be seriously influenced. Simulation achieves $90 \%$ improvement in service level.

(5) Supplier Should Set Reasonable Number of D/C. The number of hospitals wherein one $\mathrm{D} / \mathrm{C}$ responds to the pooling system will not benefit the reduction of inventory level and the improvement of liquidity in the supply chain. Designing a distribution network is only determined by the cost of building a warehouse, overhead, and distribution.

In summary, the drug pooling system is a systematic program. In its application, involved parties, such as the government, the supplier, and the hospital, should take good measure and set proper parameters to optimize inventory level and liquidity status. The new mode of drug supply chain can then address initial expectations.

\section{Competing Interests}

The authors declare that they have no competing interests.

\section{Acknowledgments}

This research is supported by the National Natural Science Foundation (NSFC) Programs of China (71661018, 71661017,91646113 and 71263029) and funded by Projects no. 20161BBA10031 and no. JC1562.

\section{References}

[1] D. Wu, Study on modes pharmacy supply in public hospital [Ph.D. dissertation], Wuhan University of Technology, Wuhan, China, 2011.
[2] X. Zhao, Q. Tang, S. Liu, and F. Liu, "Social capital, motivations, and mobile coupon sharing," Industrial Management \& Data Systems, vol. 116, no. 1, pp. 188-206, 2016.

[3] Q. Tang, X. Zhao, and S. Liu, "The effect of intrinsic and extrinsic motivations on mobile coupon sharing in social network sites: the role of coupon proneness," Internet Research, vol. 26, no. 1, pp. 101-119, 2016.

[4] Z. Deng, X. Mo, and S. Liu, "Comparison of the middle-aged and older users' adoption of mobile health services in China," International Journal of Medical Informatics, vol. 83, no. 3, pp. 210-224, 2014.

[5] Z. Deng, S. Liu, and O. Hinz, "The health information seeking and usage behavior intention of Chinese consumers through mobile phones," Information Technology \& People, vol. 28, no. 2, pp. 405-423, 2015.

[6] S. Liu and L. Wang, "Influence of managerial control on performance in medical information system projects: the moderating role of organizational environment and team risks," International Journal of Project Management, vol. 34, no. 1, pp. 102-116, 2016.

[7] S. Liu, "How the user liaison's understanding of development processes moderates the effects of user-related and project management risks on IT project performance," Information \& Management, vol. 53, no. 1, pp. 122-134, 2016.

[8] S. Liu and L. Wang, "Understanding the impact of risks on performance in internal and outsourced information technology projects: the role of strategic importance," International Journal of Project Management, vol. 32, no. 8, pp. 1494-1510, 2014.

[9] W. Pan, S. Liu, Y. Guo, and F. Wang, "Fuzzy multi-objective model for supplier selection considering multiple products in low carbon supply chain," Environmental Engineering \& Management Journal, vol. 14, no. 8, pp. 1781-1789, 2015.

[10] W. Pan, F. Wang, Y. Guo, and S. Liu, "A fuzzy multiobjective model for supplier selection under considering stochastic demand in a supply chain," Mathematical Problems in Engineering, vol. 2015, Article ID 174585, 8 pages, 2015.

[11] M. Keil, A. Rai, and S. Liu, "How user risk and requirements risk moderate the effects of formal and informal control on the process performance of IT projects," European Journal of Information Systems, vol. 22, no. 6, pp. 650-672, 2013.

[12] S. Liu, F. Xia, J. Zhang, W. Pan, and Y. Zhang, "Exploring the trends, characteristic antecedents, and performance consequences of crowdsourcing project risks," International Journal of Project Management, vol. 34, no. 8, pp. 1625-1637, 2016.

[13] S. Liu and Z. Deng, "How environment risks moderate the effect of control on performance in information technology projects: perspectives of project managers and user liaisons," International Journal of Information Management, vol. 35, no. 1, pp. 8097, 2015.

[14] H. Mao, S. Liu, J. Zhang, and Z. Deng, "Information technology resource, knowledge management capability, and competitive advantage: the moderating role of resource commitment," International Journal of Information Management, vol. 36, no. 6, pp. 1062-1074, 2016.

[15] S. Liu, "How team risk and planning and control risk moderate the effects of clan and self control on the process performance of IT projects," Information Development, vol. 31, no. 1, pp. 27-39, 2015.

[16] S. Liu, F. Xia, J. Zhang, and L. Wang, "How crowdsourcing risks affect performance: an exploratory model," Management Decision, vol. 54, no. 9, pp. 2235-2255, 2016. 
[17] S. Liu, "Effects of control on the performance of information systems projects: the moderating role of complexity risk," Journal of Operations Management, vol. 36, pp. 46-62, 2015.

[18] L. Wang, H. Qu, S. Liu, and C. Chen, "Optimizing the joint replenishment and channel coordination problem under supply chain environment using a simple and effective differential evolution algorithm," Discrete Dynamics in Nature and Society, vol. 2014, Article ID 709856, 12 pages, 2014.

[19] L. Wang, H. Qu, S. Liu, and C.-X. Dun, "Modeling and optimization of the multiobjective stochastic joint replenishment and delivery problem under supply chain environment," The Scientific World Journal, vol. 2013, Article ID 916057, 11 pages, 2013.

[20] K. Chahal, A generic framework for hybrid simulation in healthcare [Ph.D. thesis], Brunel University School of Information Systems, Computing and Mathematics, London, UK, 2010.

[21] Y. Z. Mehrjerdi, "A system dynamics approach to healthcare cost control," International Journal of Industrial Engineering, vol. 23, no. 3, pp. 175-185, 2012.

[22] J. Jia, Y. Lu, and J. Chu, "System dynamics modeling for medicine price policy in China," in Proceedings of the International Conference of the System Dynamics Society and 50th Anniversay Celebration, Boston, Mass, USA, 2007.

[23] R. L. Smith III and S. D. Roberts, "A simulation approach to exploring whole hospital system operational performance and efficiencies," in Proceedings of the IIE Annual Conference, pp. 1730-1739, 2014.

[24] A. Utami, I. Pujawan, and M. Anityasari, "Modeling supply chain contracts in pharmaceutical industry using system dynamics approach," in Proceedings of the National Seminar on Technology Management IX Study Program MMT-ITS, Surabaya, Indonesia, 2009.

[25] B. Behzad, R. J. Moraga, and S.-J. Chen, "Modelling healthcare internal service supply chains for the analysis of medication delivery errors and amplification effects," Journal of Industrial Engineering and Management, vol. 4, no. 4, pp. 554-576, 2011.

[26] S. Liu and L. Wang, "User liaisons' perspective on behavior and outcome control in IT projects: role of IT experience, behavior observability, and outcome measurability," Management Decision, vol. 52, no. 6, pp. 1148-1173, 2014.

[27] L. Wang, R. Liu, and S. Liu, "An effective and efficient fruit fly optimization algorithm with level probability policy and its applications," Knowledge-Based Systems, vol. 97, pp. 158-174, 2016.

[28] L. Wang, Y. Shi, and S. Liu, "An improved fruit fly optimization algorithm and its application to joint replenishment problems," Expert Systems with Applications, vol. 42, no. 9, pp. 4310-4323, 2015.

[29] L. Wang, Z. Wang, and S. Liu, "An effective multivariate time series classification approach using echo state network and adaptive differential evolution algorithm," Expert Systems with Applications, vol. 43, pp. 237-249, 2016.

[30] R. H. Ballou, Business Logistics: Supply Chain Management, Prentice Hall, Upper Saddle River, NJ, USA, 5th edition, 2003.

[31] S. Liu and Z. Deng, "Understanding knowledge management capability in business process outsourcing: a cluster analysis," Management Decision, vol. 53, no. 1, pp. 124-138, 2015.

[32] S. Liu, J. Zhang, M. Keil, and T. Chen, "Comparing senior executive and project manager perceptions of IT project risk: a Chinese Delphi study,' Information Systems Journal, vol. 20, no. 4, pp. 319-355, 2010. 


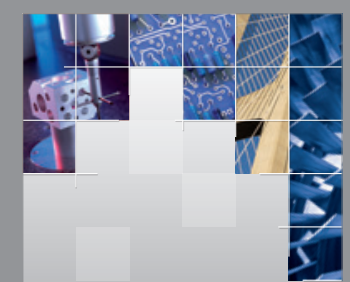

\section{Enfincering}
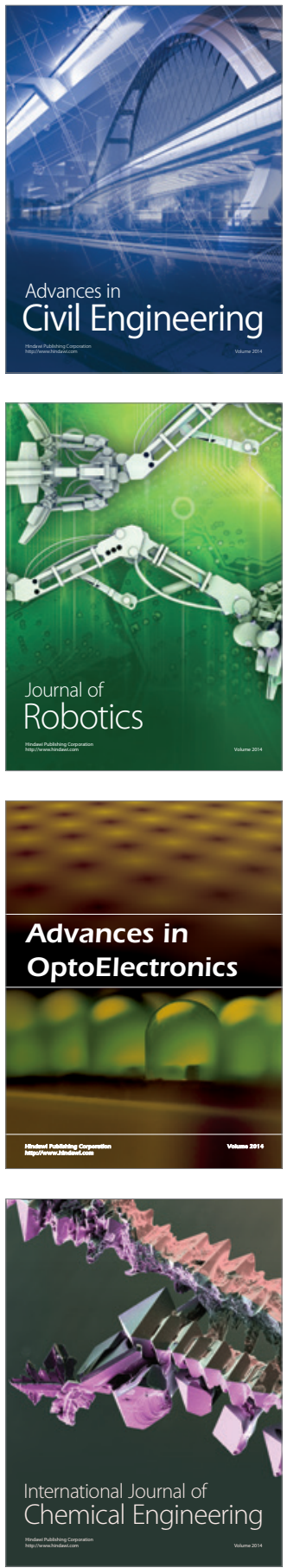

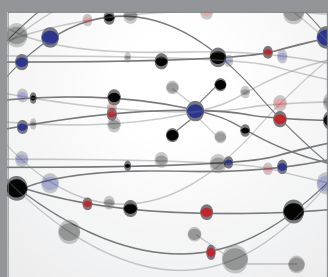

The Scientific World Journal

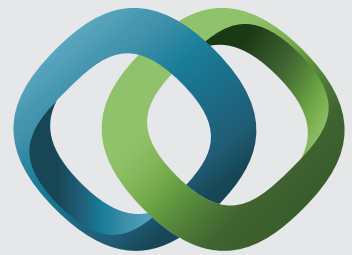

\section{Hindawi}

Submit your manuscripts at

https://www.hindawi.com
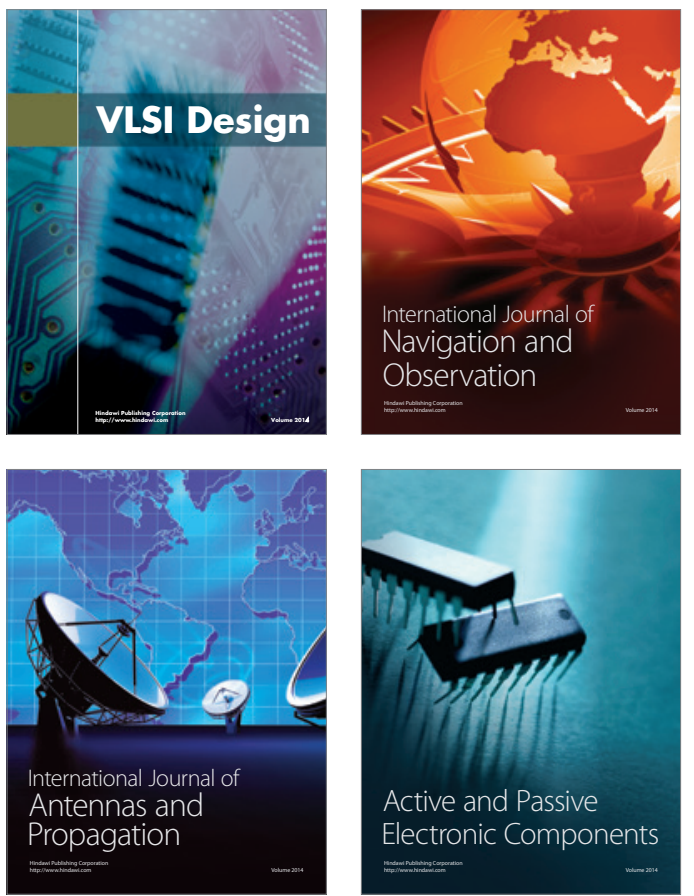
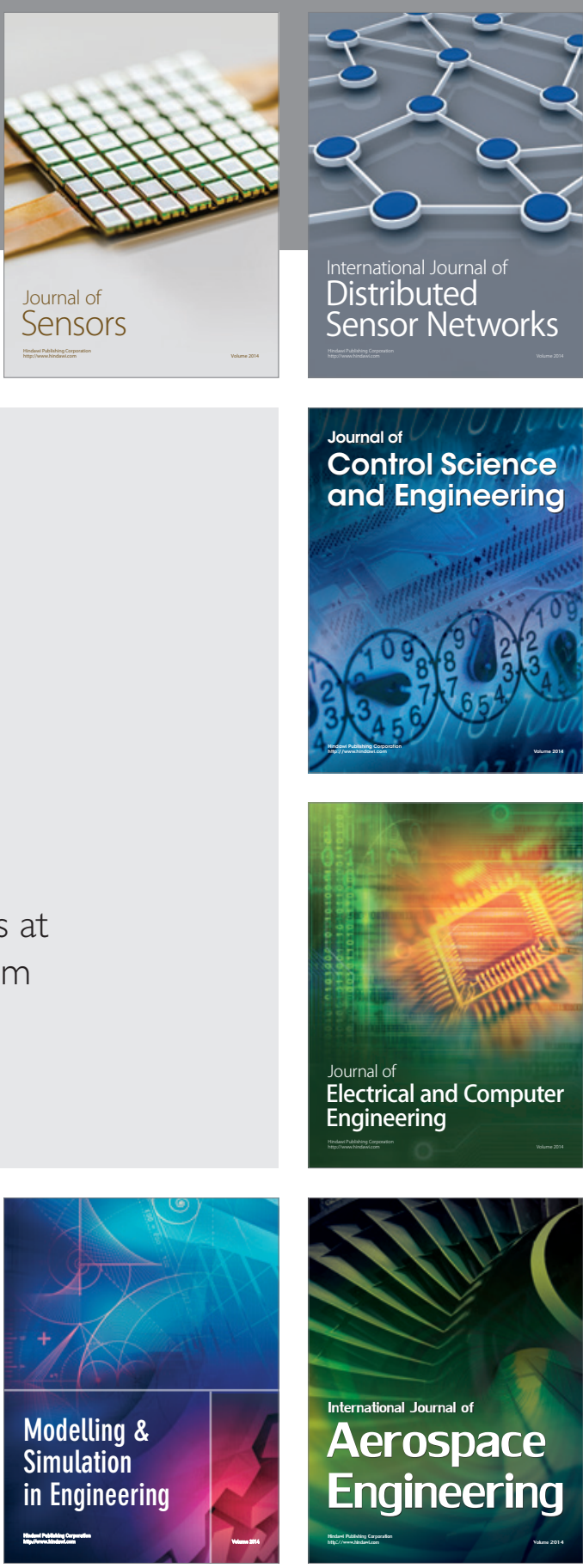

International Journal of

Distributed

Sensor Networks

$-$

Joumal of

Control Science

and Engineering
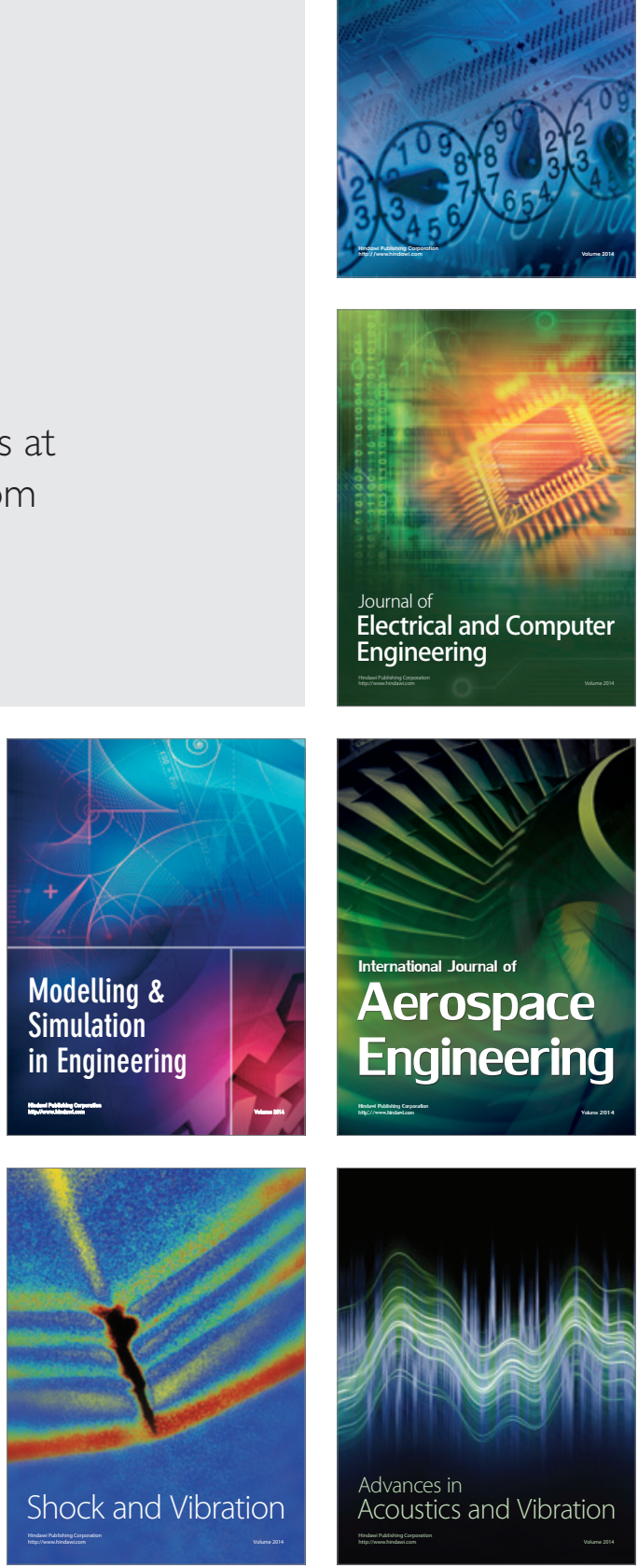